\title{
Claudin-8d is a cortisol-responsive barrier protein in the gill epithelium of trout
}

\author{
Dennis Kolosov* and Scott P Kelly \\ Department of Biology, York University, Toronto, Ontario, Canada \\ *(D Kolosov is now at Department of Biology, McMaster University, Ontario, Canada)
}

Correspondence should be addressed to S P Kelly

Email

spk@yorku.ca

\begin{abstract}
The influence of claudin (Cldn) 8 tight junction (TJ) proteins on cortisol-mediated alterations in gill epithelium permeability was examined using a primary cultured trout gill epithelium model. Genes encoding three Cldn-8 proteins ( $c / d n-8 b,-8 c$ and $-8 d$ ) have been identified in trout and all are expressed in the model gill epithelium. Cortisol treatment 'tightened' the gill epithelium, as indicated by increased transepithelial resistance (TER) and reduced paracellular [ $\left.{ }^{3} \mathrm{H}\right]$ polyethylene glycol (MW $400 \mathrm{Da}$; PEG-400) flux. This occurred in association with elevated $c / d n-8 d$ mRNA abundance, but no alterations in $c / d n-8 b$ and $-8 c$ mRNA abundance were observed. Transcriptional knockdown (KD) of cldn-8d inhibited a cortisol-induced increase in Cldn-8d abundance and reduced the 'epithelium tightening' effect of cortisol in association with increased paracellular PEG-400 flux. Under simulated in vivo conditions (i.e. apical freshwater), cldn-8d KD hindered a cortisol-mediated reduction in basolateral to apical $\mathrm{Na}^{+}$and $\mathrm{Cl}$ - flux (i.e. reduced the ability of cortisol to mitigate ion loss). However, cldn-8d KD did not abolish the tightening effect of cortisol on the gill epithelium. This is likely due, in part, to the effect of cortisol on genes encoding other TJ proteins, which in some cases appeared to exhibit a compensatory response. Data support the idea that $\mathrm{Cldn-8d}$ is a barrier protein of the gill epithelium TJ that contributes significantly to corticosteroidmediated alterations in gill epithelium permeability.
\end{abstract}

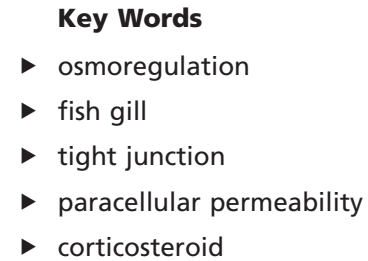

Journal of Molecular Endocrinology (2017) 59, 299-310

\section{Introduction}

The tight junction (TJ) complex acts as a selectively permeable intercellular occlusion barrier in vertebrate epithelia and contributes to the regulated paracellular movement of solutes between fluid compartments (Farquhar \& Palade 1963, Van Itallie \& Anderson 2006). The TJ complex is composed of numerous transmembrane and cytoplasmic proteins, but it is now generally accepted that transmembrane claudin (CLDN) TJ proteins that were first identified by Furuse and coworkers (1998) play a central role in establishing the permselectivity conditions of TJ occlusion (Günzel \& Yu 2013). In tetrapods, the CLDN family is large (i.e. 27 proteins in mammals), but in teleost fishes, duplication events have resulted in a considerable expansion (Loh et al. 2004), and more than half of the $+50 \mathrm{cldn}$ genes found in a teleost are expressed in the gill (Chasiotis et al. 2012b, Kolosov et al. 2013). In aquatic vertebrates, the gill presents a large surface area that directly interfaces with surrounding water. The gill plays a multifaceted role in regulating solute movement between environment and blood (Evans et al. 2005), 
and this includes limiting as well as finely controlling passive solute movement (Chasiotis et al. 2012b).

In freshwater (FW), a particularly important task for the gill epithelium is to limit diffusional ion loss (ion efflux) down electrochemical gradients into hyposmotic surroundings (Evans et al. 2005). It has been proposed that cortisol, the principal circulating corticosteroid in teleost fishes, plays a crucial role in curbing passive ion loss across the gill epithelium in FW as cortisol has been shown to elicit a dose-dependent increase in transepithelial resistance (TER) across gill epithelium models derived from FW fish gills, and this occurs in association with reduced flux of the paracellular permeability marker $\left[{ }^{3} \mathrm{H}\right]$ polyethylene glycol (PEG) (a proxy for paracellular permeability), as well as reduced $\mathrm{Na}^{+}, \mathrm{Cl}^{-}$and $\mathrm{Ca}^{2+}$ efflux rates (Kelly \& Wood 2001, 2002, 2008). This tightening effect of cortisol on the teleost fish gill epithelium is consistent with many observations of corticosteroidinduced barrier tightening in diverse vertebrate organs (e.g. Zettl et al. 1992, Stelwagen et al. 1999, Antonetti et al. 2002, Förster et al. 2005, Kwong \& Perry 2013) and is closely associated with alterations in the abundance of specific TJ proteins of the gill, including those of the Cldn superfamily (Chasiotis et al. 2010, Chasiotis \& Kelly 2011b, Kelly \& Chasiotis 2011, Kolosov et al. 2017).

The TJ protein CLDN-8 exists as a single isoform in mammals and has a putative $\mathrm{Na}^{+}$barrier function in the nephron, urinary bladder and colon (Kiuchi-Saishin et al. 2002, Yu et al. 2003, Acharya et al. 2004, Li et al. 2004, Angelow et al. 2007, Amasheh et al. 2009). In teleosts, four genes encoding Cldn-8 proteins have been described: cldn-8a, $-8 b,-8 c$ and $-8 d$ (Loh et al. 2004). These genes exhibit species-specific expression patterns in various fish organs (Kolosov et al. 2013), but in species studied so far, cldn-8d is seen to be abundant in the gill (Loh et al. 2004, Bagherie-Lachidan et al. 2009, Chasiotis \& Kelly 2012, Kolosov et al. 2014). In this regard, it is of particular interest that following cortisol treatment of a primary cultured gill epithelium model, the abundance of mRNA encoding Cldn-8d, as well as Cldn-8d protein has been reported to increase (Chasiotis \& Kelly 2011b, Kelly \& Chasiotis 2011, Kolosov et al. 2017). Because this occurs in association with reduced epithelium permeability, it would suggest that Cldn-8d is a barrier-forming TJ protein in the teleost fish gill epithelium that plays an important role in corticosteroid-associated changes in paracellular solute movement. However, there is no functional evidence to support this idea. Nevertheless, other reports suggest a barrier-forming role for Cldn-8d as well as other Cldn-8 isoforms in fishes. For example, $c l d n-8 b$ and $-8 d$ (but not $c l d n-8 c$ ) transcript abundance increase dramatically during cultured trout gill epithelium formation as well as during the development of model gill epithelium resistive properties, and this occurs in association with a significant decrease in paracellular $\left[{ }^{3} \mathrm{H}\right] \mathrm{PEG}-400$ flux (Kolosov et al. 2014). Furthermore, transcript abundance of $c l d n-8 b,-8 c$ and $-8 d$ has been shown to significantly increase in the fish gill following acclimation or exposure to an ion-poor environment (Chasiotis et al. 2012a, Kolosov \& Kelly 2016), where ion efflux rates (i.e. passive ion loss across the gill TJ complex) are documented to significantly decrease (e.g. Perry \& Laurent 1989). Most recently, it has been suggested that Cldn-8d may contribute to a cldn-31 $\mathrm{KD}$-associated increase in gill epithelium permeability because $c l d n-31 \mathrm{KD}$ appears to prevent a cortisol-stimulated increase in Cldn-8d abundance (Kolosov et al. 2017).

Taken together, previous observations suggest that Cldn-8d may play an important endocrine-mediated role in adjusting epithelial permeability of ionoregulatory epithelia in fishes and mounting evidence also suggests that Cldn-8d as well as other Cldn-8 isoforms may contribute to the barrier properties of the gill epithelium. Therefore, the goal of this study was to use a primary cultured model gill epithelium to further consider a role for Cldn-8 isoforms in corticosteroid-induced FW fish gill tightening, and more specifically, provide functional insight that goes beyond the currently documented causal association between cortisol, gill epithelium tightening and $c l d n-8 d / C l d n-8 \mathrm{~d}$.

\section{Materials and methods}

\section{Experimental animals}

Rainbow trout (Oncorhynchus mykiss, Walbaum 1792; obtained from Humber Springs Trout Hatchery, Orangeville, ON, Canada), were held in $600 \mathrm{~L}$ opaque polyethylene tanks supplied with flow-through dechlorinated freshwater (FW, composition in $\mu \mathrm{M}:\left[\mathrm{Na}^{+}\right]$ 590, $\left[\mathrm{Cl}^{-}\right]$920, $\left[\mathrm{Ca}^{2+}\right]$ 760, $\left[\mathrm{K}^{+}\right]$43, pH 7.35). Photoperiod was 12L:12D and fish were fed ad libitum once daily (Martin Profishent, Elmira, ON, Canada). Animal care and experimental procedures were in accordance with an approved York University Animal Care Committee protocol, which conformed to the guidelines of the Canadian Council on Animal Care.
() 2017 Society for Endocrinology Printed in Great Britain
Published by Bioscientifica Ltd 
Procedures for the preparation and culture of a model gill epithelium

The primary cultured model gill epithelium used in these studies was prepared using methods originally developed by Wood and Pärt (1997) and described in detail by Kelly et al. (2000). The model is composed of gill pavement cells (PVCs) only and begins with a period of flask culture, following which cells are harvested and seeded on to semi-permeable polyethylene terephthalate filter inserts $\left(0.9 \mathrm{~cm}^{2}\right.$ area, $0.4 \mu \mathrm{m}$ pore, $1.6 \times 10^{6}$ pore $/ \mathrm{cm}^{2}$ density; BD Falcon TM, BD Biosciences, Mississauga, ON, Canada). Cell culture inserts were kept in companion cell culture plates (Falcon BD) and the apical and basolateral compartments of the culture system contained L15 media supplemented with $6 \%$ fetal bovine serum.

Cultured preparations were exposed to cortisol in accordance with methods previously outlined by Kelly and Wood (2001). In brief, a concentrated stock solution of cortisol was prepared by dissolving cell culture-grade hydrocortisone 21-hemisuccinate sodium salt (SigmaAldrich) in phosphate-buffered saline (PBS, $\mathrm{pH}$ 7.7). Aliquots of stock solution were stored at $-30^{\circ} \mathrm{C}$. Upon each media change, stock cortisol solution was added to cell culture media in order to yield a final media cortisol concentration of $500 \mathrm{ng} / \mathrm{mL}$. Media containing cortisol was added to the basolateral side of cultured preparations only. Similar levels of circulating cortisol have been reported in stressed rainbow trout (Barton \& Iwama 1991).

\section{Measurement of transepithelial resistance (TER) and [3H] PEG-400 flux}

TER of insert-cultured preparations was monitored with chopstick electrodes (STX-2) attached to a custommodified EVOM epithelial voltohmmeter (World Precision Instruments, Sarasota, FL, USA). Paracellular flux of $\left[{ }^{3} \mathrm{H}\right] \mathrm{PEG}-400$ (American Radio Chemicals, St. Lois, MO, USA) was measured and calculated according to Wood and coworkers (1998).

\section{Quantitative real-time PCR (qPCR) analysis of cldn-8 mRNA abundance}

Transcript abundance of $c l d n-8 b,-8 c$ and $-8 d$ in control and cortisol-treated model gill epithelia was determined using primer sets and techniques described in detail by Kolosov and coworkers (2014). In brief, total RNA was isolated from gill tissue using TRIzol Reagent (Invitrogen Canada Inc., Burlington, ON, Canada) according to manufacturer's instructions and quantified using a Multiskan Spectrum UV/Vis microplate spectrophotometer (Thermo Fisher Scientific). Total RNA $(2 \mu \mathrm{g})$ was treated with DNase I (Amplifications Grade, Invitrogen Canada, Inc.) and used for cDNA synthesis with SuperScriptTM III reverse transcriptase and Oligo(dT)12-18 primers (Invitrogen Canada, Inc.). Transcript abundance of $c l d n-8 b$ (GenBank accession \# BK008770.1; forward: ACGACTCCCTCCTGGCTCT and reverse: GAGACCCATCCGATGTAGA; predicted amplicon size 185bp), cldn-8c (GenBank accession \# BK008771.1; forward: GCTTGATGTGCTGCTCTC and reverse: CCCAGAGGTCAGGAGGA; predicted amplicon size 201 bp) and cldn-8d (GenBank accession \# BK007966.1; forward: GCAGTGTAAAGTGTACGACTCTCTG and reverse: CACGAGGAACAGGCATCC; predicted amplicon size $200 \mathrm{bp}$ ) was examined with SYBR Green I Supermix (Bio-Rad Laboratories Canada Ltd) in a Chromo4TM Detection System (CFB-3240; Bio-Rad Laboratories Canada Ltd). Reaction conditions were 1 denaturation cycle $\left(95^{\circ} \mathrm{C}, 4 \mathrm{~min}\right)$, followed by 40 cycles of: denaturation $\left(95^{\circ} \mathrm{C}, 30 \mathrm{~s}\right)$, annealing $\left(\mathrm{cldn}-8 b 56^{\circ} \mathrm{C}\right.$; cldn $-8 \mathrm{c} 60^{\circ} \mathrm{C}$; cldn-8d $\left.60^{\circ} \mathrm{C}, 30 \mathrm{~s}\right)$ and extension $\left(72^{\circ} \mathrm{C}, 30 \mathrm{~s}\right)$. A dissociation curve analysis was carried out after each qPCR run to confirm the synthesis of a single PCR product. Rainbow trout elongation factor 1-alpha (ef-1a; GenBank accession \# AF498320.1; forward: GGCAAGTCAACCACCACAG and reverse: GATACCACGCTCCCTCTCAG; predicted amplicon size $159 \mathrm{bp}$ ) was used as a reference gene. The use of ef-1a as a reference for gene of interest normalization was validated by statistically comparing ef- $1 a$ threshold cycles between treatments to confirm that experimental conditions had not significantly altered the values. Transcript encoding rainbow trout $c l d n-8 a$ was not examined in this study because we have been unable to identify a $c l d n-8 a$ homolog in this species.

\section{Western blot, immunocytochemistry and Cldn-8d protein quantification}

Western blot analysis of Cldn-8d was conducted using methods previously described by Chasiotis and coworkers (2010). Briefly, insert-cultured cells were rinsed with ice-cold PBS $\left(4^{\circ} \mathrm{C}\right)$, and then incubated in a lysis buffer (10 mM Tris- $\mathrm{HCl}, \mathrm{pH}=7.5,1 \mathrm{mM}$ EDTA, $0.1 \mathrm{mM} \mathrm{NaCl}$, $1 \mathrm{mM}$ PMSF) with 1:200 protease inhibitor cocktail (Sigma-Aldrich Canada Ltd.). Epithelial tissue was then collected after disruption by repeatedly passing cells in solution through a $26 \mathrm{G}$ syringe needle. A supernatant was collected following centrifugation $(10,000 \boldsymbol{g}$ for

Published by Bioscientifica Ltd. 
$10 \mathrm{~min}, 4^{\circ} \mathrm{C}$ ) and protein concentration of this solution was determined using a Bradford Assay (Sigma-Aldrich Canada Ltd.). A total of $5 \mu \mathrm{g}$ protein was then used for Western blotting using a 12\% SDS-PAGE gel. Wet transfer was performed to transfer protein samples from the gel to a polyvinylidene difluoride (PVDF) membrane at $100 \mathrm{~V}$ for $1 \mathrm{~h}$. Following transfer, the membrane was incubated with 5\% skimmed milk solution for $1 \mathrm{~h}$ at room temperature (RT), after which the membrane was incubated overnight at RT with a rabbit anti-Cldn-8d custom synthesized antibody. The custom synthesized Cldn-8d polyclonal antibody was raised in rabbit against a synthetic peptide (Ac-SYFDPAYDEKAAKSC-amide) corresponding to a 16-29 amino acid region of rainbow trout Cldn-8d (New England Peptide, LLC, Gardner, MA, USA) (1:1000 dilution in Tris-buffered saline with Tween; TBS-T, $10 \mathrm{mM}$ Tris, $150 \mathrm{mM} \mathrm{NaCl}, 0.05 \%$ Tween-20, $\mathrm{pH}=7.4)$. Signal detection was performed by incubating the membrane with a horseradish peroxidase (HRP)conjugated goat anti-rabbit secondary antibody (Bio-Rad Laboratories Canada Ltd.; $1 \mathrm{~h}, \mathrm{RT})$. Antigen reactivity was examined with Clarity Western ECL Blotting Substrate (Bio-Rad Laboratories Canada Ltd.; 5 min at RT). Imaging of Cldn-8d immunoreactivity (Cldn-8d-ir) was conducted using a Chemi-Doc MP System (Bio-Rad Laboratories Canada Ltd.). Specificity of the custom-made primary antibody was confirmed using a peptide pre-absorption technique described by Bui and Kelly (2014).

Procedures for the immunolocalization of Cldn-8d in cultured gill epithelia are outlined in detail in Chasiotis and Kelly (2011a). Briefly, insert-cultured gill epithelium preparations were fixed with $3 \%$ paraformaldehyde, permeabilized with ice-cold methanol for $5 \mathrm{~min}$ at $-20^{\circ} \mathrm{C}$, rinsed with Triton X-100 in phosphate-buffered saline (PBS) and incubated with antibody-dilution buffer (ADB; $10 \%$ goat serum, $3 \%$ BSA and $0.05 \%$ Triton X-100 in PBS; $1 \mathrm{~h}$ at RT). Preparations were then incubated with the custom anti-Cldn-8d antibody (as detailed previously; overnight at RT, 1:100 in ADB). After washing in PBS, epithelia were incubated with a TRITC-labeled goat anti-rabbit antibody (1:500 in ADB; Jackson ImmunoResearch Laboratories; $1 \mathrm{~h}$ at RT). Preparations were then mounted on slides with mounting medium containing 4',6-diamidino-2phenylindole (DAPI) for nuclear visualization. Images of Cldn-8d-ir and DAPI fluorescence were captured using a differential interference contrast (DIC) and laserscanning confocal microscopy with an Olympus BX-51 in conjunction with a Fluoview unit and MellesGriot green and red argon lasers (Olympus Canada). As a negative control, epithelia were prepared as previously described in the absence of primary antibody.

For quantification of Cldn-8d protein abundance, Western blot analysis was used to image Cldn-8d-ir as described previously. Membranes were then incubated in stripping buffer, blocked with $5 \%$ skim milk solution as outlined above and incubated with mouse monoclonal anti-actin JLA20 antibody (Developmental Studies Hybridoma Bank, Iowa City, USA), as a reference protein. Actin immunoreactivity was imaged and used to normalize Cldn-8d abundance after validating, by statistical comparison, that actin abundance was not influenced by experimental treatment. Cldn-8d and actin protein abundance were quantified using ImageJ software (National Institutes of Health, Java 1.6.0_45 (64-bit)).

\section{Transcriptional knockdown (KD) of $c l d n-8 d$}

Methods followed for transcriptional KD of $c l d n-8 d$ have been reported by Kolosov and coworkers (2017). Custommade double-stranded RNA (dsRNA) spanning nucleotides 64-548 of the cldn-8d transcript (GenBank accession \# BK007966.1) was prepared using a T7 RiboMAX Express RNAi System (Promega) according to the manufacturer instructions. dsRNA concentration was determined using a NanoDrop 2000 spectrophotometer (Thermo Fisher Scientific) and 15-60pmol was used for cldn-8d KD in cultured preparations combined with Lipofectamine 3000 transfection reagent (Invitrogen Canada Inc.). A range of 15-60 pmol of dsRNA was found to be effective; therefore, subsequent experiments were conducted with $15 \mathrm{pmol}$ dsRNA, where epithelia were first transfected $24 \mathrm{~h}$ after seeding on to cell culture inserts.

For analysis of cldn-8d transcript in transfected tissue, total RNA was isolated and cDNA synthesized as previously described (see Quantitative real-time PCR (qPCR) analysis of cldn-8 mRNA abundance section). The presence of $c l d n-8 d$ mRNA was then determined by reverse transcriptase PCR (RT-PCR). In order to detect transcriptional KD of $c l d n-8 d$, a separate set of primers for rainbow trout $c l d n-8 d$ were designed using the coding sequence (forward: 5'-TACGACGAGAAAGCAGCAAA-3' and reverse: 5'-ATTGGGATGATGGTGGTGAC-3', predicted amplicon size $\sim 490 \mathrm{bp}$ ). PCR conditions used were as follows: denaturation at $95^{\circ} \mathrm{C}, 4 \mathrm{~min}$, followed by 40 cycles of: (1) denaturation $\left(95^{\circ} \mathrm{C}, 30 \mathrm{~s}\right)$, (2) annealing $\left(60^{\circ} \mathrm{C}, 30 \mathrm{~s}\right)$ and (3) extension $\left(72^{\circ} \mathrm{C}\right.$, $30 \mathrm{~s})$. RT-PCR product was examined using agarose gel electrophoresis. http://jme.endocrinology-journals.org DOI: 10.1530/JME-17-0108
() 2017 Society for Endocrinology Printed in Great Britain
Published by Bioscientifica Ltd 
Ion flux measurements under asymmetrical culture conditions

Using ion-selective microelectrodes (ISMe) constructed according to Donini and O'Donnell (2005), net flux rates of $\mathrm{Na}^{+}$were determined under asymmetrical cultures conditions (i.e. apical FW/L15 basolateral) using apical FW collected at the start and at the end of a 2-h flux period. When introduced to the experimental setup, apical FW was sterile, temperature equilibrated and the same composition as fish holding water (see Experimental animals section). Flux rates (efflux; basolateral to apical movement) were calculated as the difference between ion concentration at the beginning and the end of FW exposure over time and surface area. To measure $\mathrm{Cl}^{-}$flux rates, the same samples were used to examine $\left(\mathrm{Cl}^{-}\right)$colorimetrically as described by Zall and coworkers (1956).

\section{Transcriptional analysis of genes encoding cortisol- responsive cldns}

To examine how cldn-8d KD influenced the transcriptional response of other cortisol-responsive cldns, cldn-3a (BK007964), -6 (KF445436), -7 (BK007965), -12 (BK007967), -20a (BK009404), -23a (BK008775), -28b (EU921670), -30 (BK007968) and -31 (BK007969) were chosen for examination in accordance with the observations of Kelly and Chasiotis (2011), Kolosov and coworkers (2014) and Gauberg and coworkers (2017). Transcript abundance of cldns were examined by qPCR using techniques as outlined above, previously published primer sets (Kelly \& Chasiotis 2011, Kolosov et al. 2014, Gauberg et al. 2017) and cDNA were prepared using symmetrically cultured cells.

\section{Statistical analysis}

Statistical analysis was conducted using a Student's $t$-test or a two-way ANOVA protocol coupled with a multiple comparison test where appropriate, in SigmaPlot (version 11) statistical software. Statistical significance was based on the observation of a fiduciary limit of $P<0.05$.

\section{Results}

Effect of cortisol on model gill epithelium permeability, cldn-8 isoform mRNA abundance and Cldn-8d abundance

Cortisol treatment of the cultured gill epithelium increased TER (Fig. 1A) and decreased paracellular
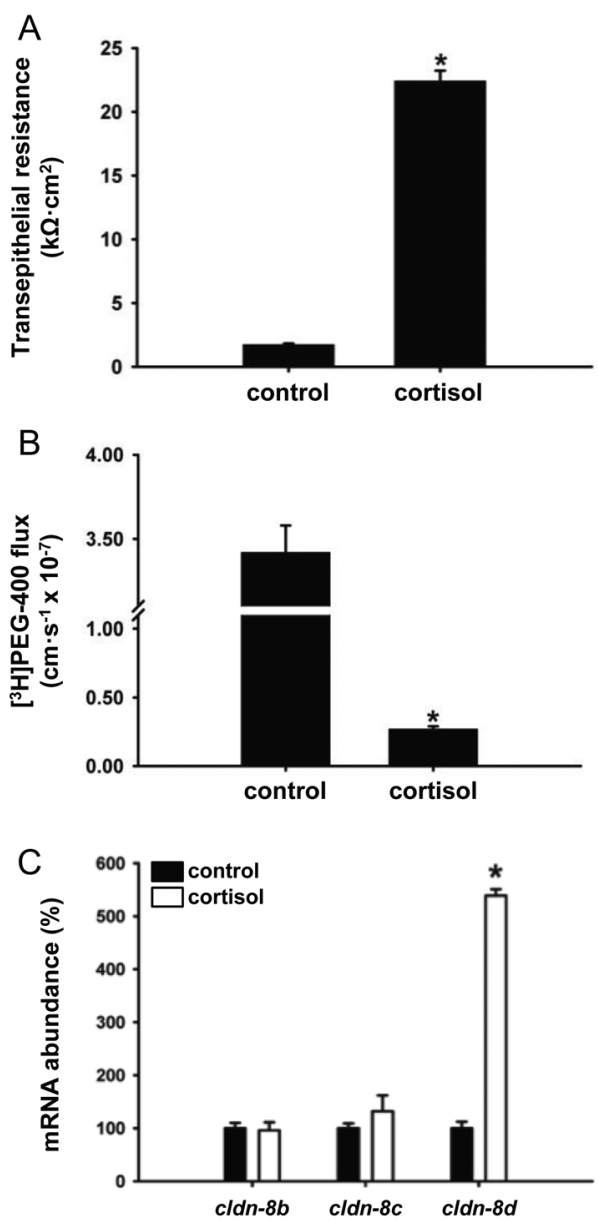

Figure 1

Cortisol reduces gill epithelium permeability and selectively alters claudin (cldn) 8 isoform transcript abundance. Effect of cortisol on (A) transepithelial resistance, (B) [3H]PEG-400 flux and (C) $c l d n-8 b,-8 c$ and $-8 d$ transcript abundance. All data are expressed as mean values \pm S.E.M. $(n=5)$. Transcript abundance of $c l d n-8 b,-8 c$ and $-8 d$ is normalized using rainbow trout elongation factor $1 \mathrm{a}$ as a reference gene and transcript abundance of $c l d n-8$ genes in cortisol-treated preparations (open bars) are expressed relative to control preparations assigned a value of 100 (closed bars). An asterisk indicates significant difference $(P<0.05)$ between cortisol-treated and control epithelia as determined by an unpaired Student's $t$-test.

[3H]PEG-400 flux (Fig. 1B). Cortisol treatment did not alter the transcript abundance of $c l d n-8 b$ or $-8 c$, but significantly increased $c l d n-8 d$ transcript abundance (Fig. 1C). A custom-synthesized antibody raised against rainbow trout Cldn-8d resolved as a single band of $\sim 38 \mathrm{kDa}$ by Western blot analysis of gill epithelium tissue (Fig. 2A). Cldn-8d localized to regions of cell-to-cell contact around the periphery of cultured gill epithelium cells (Fig. 2B). Cortisol treatment significantly increases Cldn-8d abundance in the cultured gill epithelium preparation (Fig. 2C).
๑ 2017 Society for Endocrinology Printed in Great Britain 
A +peptide

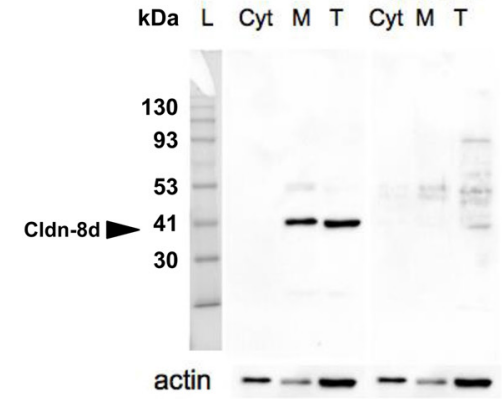

B

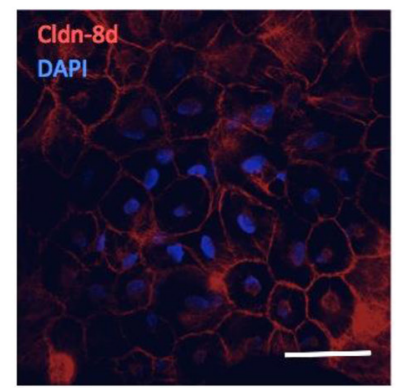

C

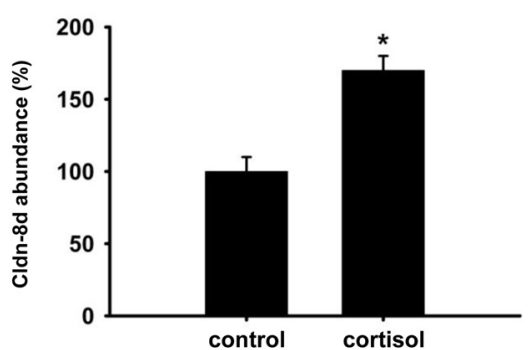

Figure 2

Claudin (Cldn)-8d protein localizes to regions of cell-to-cell contact in the gill epithelium and increases in abundance following cortisol treatment. (A) Western blot analysis of a custom-synthesized rainbow trout Cldn-8d antibody in primary cultured gill epithelium tissue revealed a single immunoreactive band of $\sim 38 \mathrm{kDa}$ in total $(\mathrm{T})$ and membrane $(\mathrm{M})$ fractions but not in the cytosolic (Cyt) fraction. This band was not present following a peptide block procedure (+ peptide). In panel (B), Cldn-8d (red) can be seen immunolocalized to regions of cell-to-cell contact around the periphery of cultured gill cells and nuclear DAPI staining can be seen in blue (scale bar $=100 \mu \mathrm{m})$. Panel $(C)$ shows the effect of cortisol on Cldn-8d abundance as determined by Western blot analysis. Data in panel (C) are expressed as mean values \pm S.E.M. $(n=5)$ and a significant difference $(P<0.05)$ between cortisol-treated and control epithelia as determined by an unpaired Student's $t$-test, is indicated by an asterisk. A full colour version of this figure is available at http://dx.doi.org/10.1530/JME-17-0108.

\section{Effect of cortisol and cldn-8d KD on model gill epithelium permeability}

Using dsRNA to $\mathrm{KD}$ cldn- $8 d$ resulted in complete elimination of transcript $24 \mathrm{~h}$ post transfection (Fig. 3A). This occurred at the three doses tested (i.e. 15, 30 and 60 pmol dsRNA). An amplicon of expected size was seen in untreated controls and in cultured preparations transfected with negative control dsRNA designed for a bacterial transcript (Fig. 3A). Cldn-8d protein abundance was examined 24,48 and $72 \mathrm{~h}$ after dsRNA transfection and was found to be significantly reduced $(\sim 50 \%)$ and stable vs epithelia transfected with negative control dsRNA (Fig. 3B). In control and cortisol-treated preparations, $c l d n-8 d$ KD significantly reduced cortisol-stimulated TER (Fig. 3C). A significant increase in paracellular PEG-400
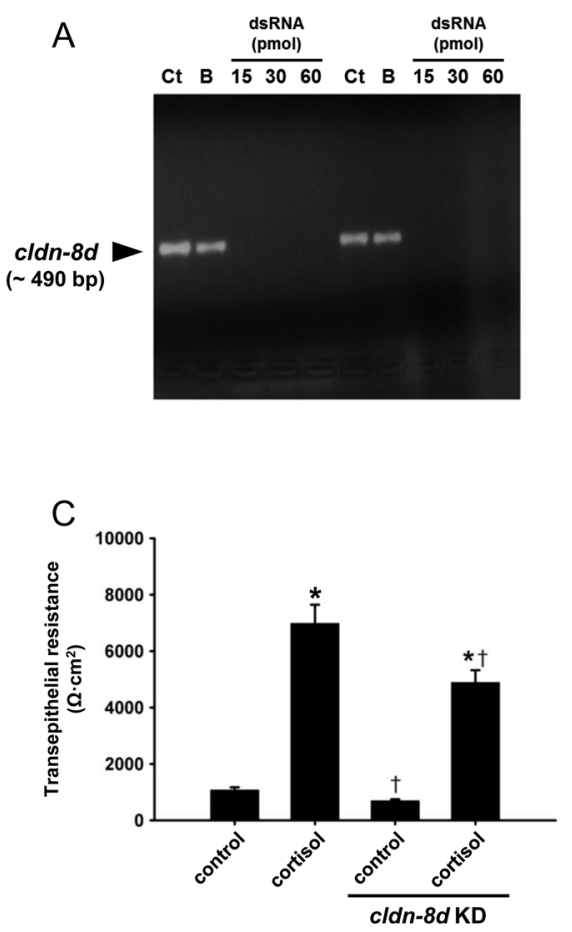

B

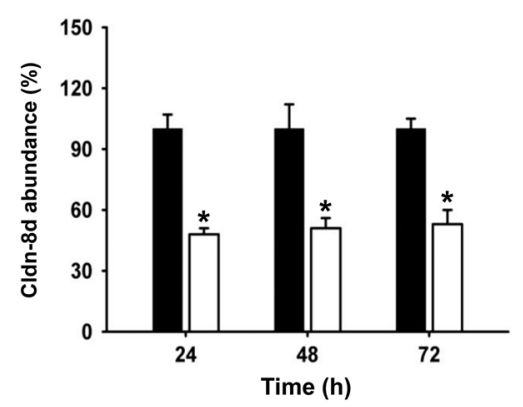

D

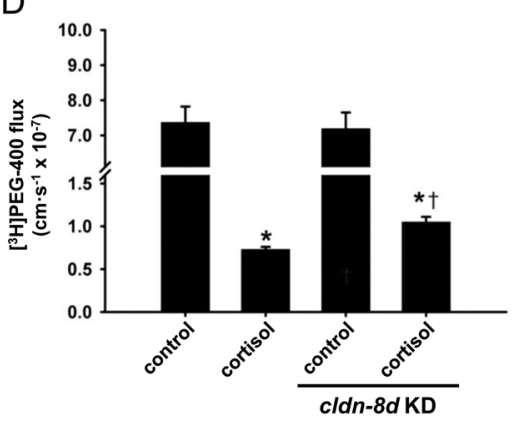

Figure 3

Transcriptional knockdown (KD) of cldn-8d in the gill epithelium reduces $\mathrm{Cldn}-8 \mathrm{~d}$ abundance and increases permeability of control and cortisoltreated preparations. The effect of $c l d n-8 d$ KD on (A) RT-PCR amplification of $c / d n-8 d 24 \mathrm{~h}$ following transcriptional KD and (B) Cldn-8d protein abundance as well as (C) transepithelial resistance and (D) paracellular [ $\left.{ }^{3} \mathrm{H}\right] \mathrm{PEG}-400$ flux across a primary cultured model gill epithelium. Panel (A) shows RT-PCR-generated $c l d n-8 d$ amplicons run on an agarose gel. Tissue for PCR analysis was harvested $24 \mathrm{~h}$ following transcriptional KD with dsRNA ( $\mathrm{Ct}=$ untreated control, $\mathrm{B}=$ bacterial nonsense dsRNA, and 15,30 , and $60=$ dose, in pmol, of dsRNA used for cldn-8d KD). In panels $(B, C$ and $D)$, all data are expressed as mean values \pm S.E.M. In panel (B), Cldn- $8 \mathrm{~d}$ abundance is shown for tissue collected 24,48 and $72 \mathrm{~h}$ following cldn-8d KD ( $n=4 /$ group). An asterisk indicates significant difference $(P<0.05)$ between control and cldn-8d KD groups as determined by an unpaired Student's $t$-test. In panels (C) and (D), permeability endpoints were determined using epithelium preparations bathed on both sides with L15 medium that had plateaued (i.e. mature preparations, $n=8$ /group); an asterisk indicates the significant difference due to cortisol treatment, while daggers indicate significance due to $c / d n-8 d \mathrm{KD}$, as determined by a two-way ANOVA coupled with a Holm-Sidak post hoc test. 
flux was also observed in cortisol-treated cldn-8d KD preparations (Fig. 3D).

\section{Effect of cortisol and cldn-8d KD on model gill epithelium permeability, Cldn-8d abundance and ion flux rates under simulated in vivo conditions}

In cortisol-treated cultured gill epithelium preparations exposed to simulated in vivo conditions (i.e. apical FW/basolateral L15), TER was elevated (Fig. 4A) and Cldn-8d abundance was increased vs control epithelia (Fig. 4B). In addition, net $\mathrm{Na}^{+}$and $\mathrm{Cl}^{-}$flux rates (i.e. basolateral to apical ion movement; equivalent to ion loss) were decreased (Fig. 4C and D). However, under the same asymmetrical culture conditions, cldn8-d KD reduced a cortisol-stimulated increase in TER (Fig. 4A) and Cldn-8d abundance (Fig. 4B). Flux (i.e. basolateral to apical movement) rates of $\mathrm{Na}^{+}$and $\mathrm{Cl}^{-}$were elevated by $c l d n-8 d \mathrm{KD}$ in control preparations (Fig. 4C and D), and the cortisol-induced reduction in ion flux rates as described previously was also significantly impaired by cldn- $8 d \mathrm{KD}$ (Fig. 4C and D). Nevertheless, when comparing cldn-8d KD control and cortisol-treated preparations, an effect of cortisol could still be seen (Fig. 4A, B, C and D).

\section{Effect of cortisol and cldn-8d KD on cortisol-responsive model gill epithelium cldn isoform mRNA abundance}

Cortisol treatment significantly elevated the transcript abundance of cldn-3a, -6, -7, -12, -20a, -23a, -28b,
-30 and -31 in the model gill epithelium (Fig. 5). In cldn-8d KD preparations, a significant increase in the transcript abundance of these cldns (vs control cldn-8d KD epithelia) was also observed for all isoforms except for cldn-3a. In the absence of cortisol, cldn- $8 d \mathrm{KD}$ resulted in an increase in $c l d n-7,-12$ and -20a mRNA abundance. An increase in mRNA abundance of cldn-7 and -12 was also observed as a result of $c l d n-8 d \mathrm{KD}$ in the presence cortisol (i.e. when comparing cortisol vs cortisol cldn-8d KD groups). However, the same trend was absent for $c l d n-20 a$, which exhibited no significant difference between cortisol and cortisol cldn-8d KD preparations.

\section{Discussion}

\section{Overview}

Data from this study provide functional evidence that Cldn-8d plays an important role in cortisol-induced gill epithelium tightening and that Cldn-8d may be the only cortisol-responsive Cldn-8 isoform in the gill epithelium of rainbow trout. More specifically, $c l d n-8 d \mathrm{KD}$ limited, but did not eliminate, the tightening effect of cortisol on a model gill epithelium composed of PVCs. These observations are not unexpected because there are numerous gill TJ proteins that are transcriptionally responsive to cortisol and many of these encode either putative or known barrier-forming TJ proteins. Furthermore, the ability of $c l d n-8 \mathrm{~d}$ KD to limit but not abolish cortisol-induced tightening of the primary cultured model PVC epithelium used in this study is

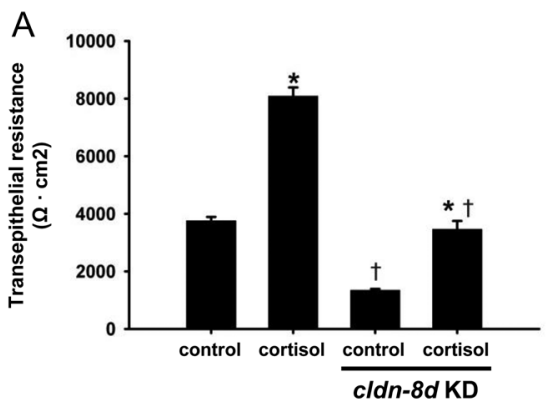

C

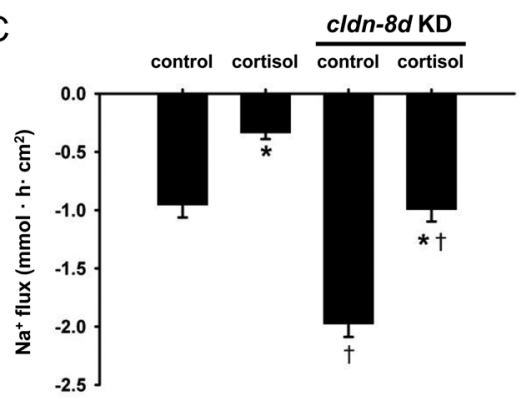

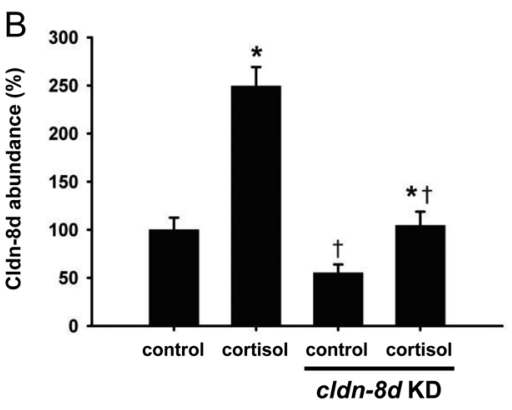

D

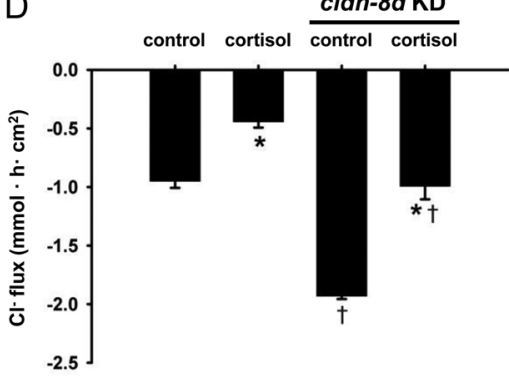

Figure 4

Transcriptional knockdown (KD) of cldn-8d in the gill epithelium inhibits cortisol-induced alterations in permeability, Cldn-8d abundance and ion flux rates ( $\equiv$ ion loss) under simulated in vivo conditions. The effect of $c / d n-8 d \mathrm{KD}$ and cortisol treatment on (A) transepithelial resistance (TER), (B) Cldn-8d abundance, (C) net $\mathrm{Na}^{+}$flux (三 $\mathrm{Na}^{+}$efflux) and (D) net $\mathrm{Cl}^{-}$flux ( $\equiv$ to $\mathrm{Cl}^{-}$efflux) in cultured gill epithelium preparations exposed to asymmetrical culture conditions (i.e. simulated in vivo conditions; apical freshwater/basolateral $\mathrm{L} 15)$ for $2 \mathrm{~h}$. All data are expressed as mean values \pm S.E.M. (A) $n=5 /$ group, (B) $n=10 /$ group, (C) $n=5 /$ group, (D) $n=5 /$ group. An asterisk indicates a statistically significant difference $(P<0.05)$ between control and cortisol-treated groups while a dagger denotes a significant difference due to $c / d n-8 d K D$, as determined by a two-way ANOVA coupled with a Holm-Sidak post hoc test. 


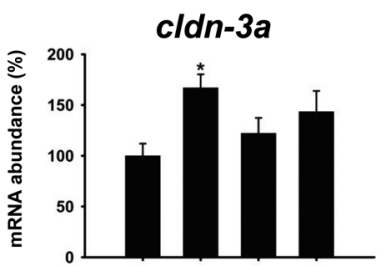

cldn-12

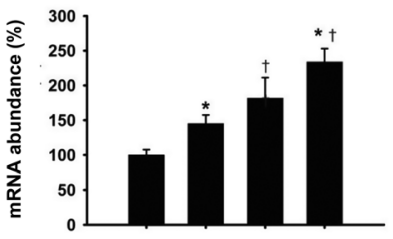

cldn-28b

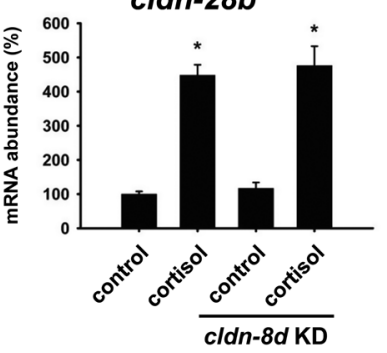

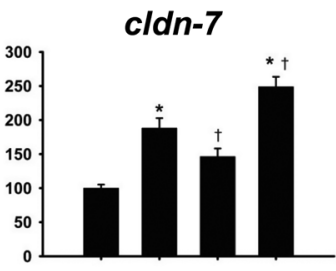

cldn-20a

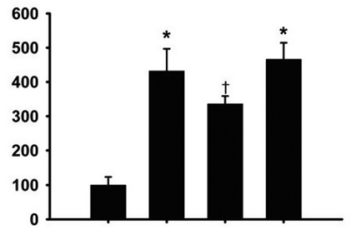

cldn-30

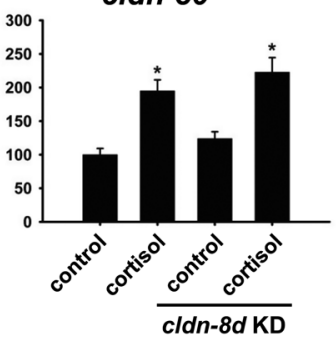

cldn-23a

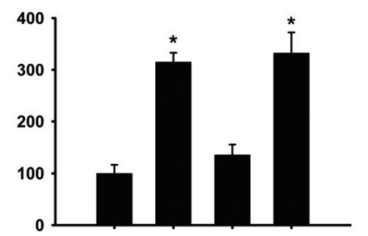

c/dn-31

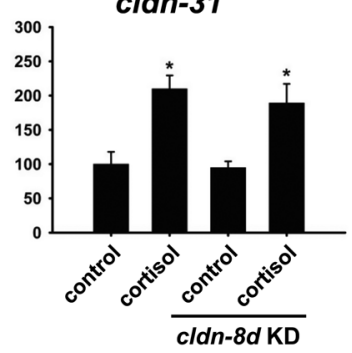

Figure 5

Transcriptional knockdown (KD) of cldn-8d in the gill epithelium alters the transcript abundance of select cortisol-responsive cldn isoforms. The effect of cldn-8d KD and cortisol treatment on transcript abundance of cldn-3a, -6, -7, -12, -20a, -23a, -28b, -30 and -31 in a primary cultured gill epithelium model. Transcript abundance of each cldn isoform was normalized using trout elongation factor $1 \mathrm{a}$ as a reference gene and expressed relative to the untreated control group (control) assigned a value of 100. Data are expressed as mean values \pm S.E.M. ( $n=5$ or $6 /$ group). An asterisk indicates a statistically significant difference $(P<0.05)$ between control and cortisol-treated groups while a dagger denotes a significant difference due to $c l d n-8 d \mathrm{KD}$, as determined by a two-way ANOVA coupled with a Holm-Sidak post hoc test. consistent with the effect of $c l d n-31 \mathrm{KD}$, which was also shown to have a similar effect on model gill epithelium permeability (Kolosov et al. 2017). However, although Cldn-31 contributed to cortisol-induced epithelium tightening, some ambiguity remains as to how much of a role it plays because $c l d n-31$ KD prevented a cortisolinduced increase in Cldn-8d abundance, which may have enhanced increased permeability (Kolosov et al. 2017). In contrast, this study suggests that $c l d n-8 d \mathrm{KD}$ compromises gill PVC epithelium integrity without negatively affecting other cortisol-responsive cldns in PVCs, including cldn-31. The importance of Cldn-8d as a cortisol-responsive barrier protein in the gill epithelium TJ complex can ultimately be seen in asymmetrically exposed (apical FW) KD preparations that manifest a weakened ability to mitigate $\mathrm{Na}^{+}$and $\mathrm{Cl}^{-}$flux (三 ion loss). These observations support the idea that in a natural setting where the gill epithelium is exposed to FW on the apical surface, Cldn-8d contributes significantly to gill epithelium tightness and that this contribution can be modulated by alterations in circulating cortisol levels.

The effect of cortisol on permeability and cldn-8 isoform abundance in the gill epithelium and characterization of Cldn-8d

The tightening effect of corticosteroids on vertebrate epithelia/endothelia is well documented across a broad array of tissue barrier types, but was first reported for a fish epithelium using a cultured trout gill model (Kelly \& Wood 2001). It has since been shown to occur in cultured gill epithelia derived from other species (Kelly \& Wood 2002, Chasiotis \& Kelly 2011b, 2012) as well as intact fish (Kwong \& Perry 2013), and this takes place in association with changes in the molecular physiology of the TJ complex (Chasiotis et al. 2010, Kelly \& Chasiotis 2011, Kolosov \& Kelly 2013). However, from a mechanistic standpoint, almost nothing is known about how different $\mathrm{TJ}$ components contribute to this endocrine-mediated physiological change. In this study, we confirm that gill epithelium $c l d n-8 d$ mRNA abundance increases in response to cortisol, and that this occurs in association with reduced paracellular PEG flux (a proxy for paracellular permeability). In addition, we are able to suggest that $c l d n-8 d$ may be the only cortisol-responsive $c l d n-8$ isoform in the trout gill epithelium because neither $c l d n-8 b$ nor $-8 c$ mRNA alter following cortisol treatment. Whether this will be a species and/or organ specific phenomenon remains to be determined as we are unaware of any other study that has examined the effect of corticosteroids on cld $n-8 b$ or $-8 c$.

Cldn-8d was found to localize around the periphery of cultured gill epithelium cells at regions of cell-tocell contact. This is consistent with the localization of a bicellular TJ protein in a vertebrate epithelium. Using

Published by Bioscientifica Ltd. 
Western blot analysis, Cldn-8d resolved as a single band of $\sim 38 \mathrm{kDa}$. This is larger than the $\sim 25 \mathrm{kDa} \mathrm{MW}$ of mammalian CLDN-8, which was first described by Morita et al. (1999), but it is not unusual for a CLDN TJ protein. For example, CLDN-16 and CLDN-23 are $\sim 34$ and $\sim 32 \mathrm{kDa}$, respectively (Simon et al. 1999, Katoh \& Katoh 2003). It was also confirmed that Cldn-8d abundance increases following cortisol treatment, which is consistent with previous observations (Kolosov et al. 2017).

\section{The effect of cldn-8d KD and cortisol on gill epithelium permeability}

Transcriptional KD of cldn- $8 d$ significantly reduced Cldn-8d protein abundance at the first time point examined (i.e. $24 \mathrm{~h}$ following transfection). At this time, no RT-PCR-amplified cldn-8d amplicon was observed in cultured preparations and protein abundance was $~ 50 \%$ reduced. This reduction in Cldn-8d abundance was observed for at least $72 \mathrm{~h}$ following $c l d n-8 d \mathrm{KD}$. There did not appear to be any time-dependent change in Cldn-8d abundance following $c l d n-8 d \mathrm{KD}$. Because the estimated half-life of Cldn-8d in a vertebrate in vitro model (as calculated using ProtParam ExPaSy online tool; http:// web.expasy.org/cgi-bin/protparam/protparam) is $\sim 30 \mathrm{~h}$, this apparent absence of time-dependent change could be due to an orchestrated balance of residual, pre-KD Cldn-8d protein during the early stages of $\mathrm{KD}$ and the appearance of new protein as the system recovers during the later stages of KD. Nevertheless, cldn- $8 d \mathrm{KD}$ (and a reduction in Cldn-8d abundance) was coupled with a reduction in TER of gill epithelium preparations both in the presence and absence of cortisol. However, a significant effect of $c l d n-8 d \mathrm{KD}$ on paracellular PEG flux was only seen in cortisol-treated preparations. In this case, these results obscure a definitive conclusion regarding the nature of Cldn-8d as a putative barrier protein, although they do support the idea that Cldn-8d plays an important barrier-forming role in cortisol-induced gill epithelium tightening. But the aforementioned results are generated using model preparations held under symmetrical culture conditions (i.e. L15 apical/L15 basolateral), which does not present the demands experienced by a tissue exposed to solute asymmetry such as that faced by the FW fish gill epithelium (i.e. apical FW/basolateral blood). Therefore, more compelling evidence that Cldn-8d is a barrier protein in the gill epithelium can be seen when considering how cldn-8d KD preparations cope with exposure to apical FW. In control $c l d n-8 d \mathrm{KD}$ preparations, decreased TER was observed as before, and this was coupled with an increase in net $\mathrm{Na}^{+}$and $\mathrm{Cl}^{-}$flux, which in these preparations is equivalent to paracellular efflux rates or ion loss (Wood et al. 1998). The ability of cortisol to mitigate ion loss under asymmetrical conditions was compromised by cldn- $8 d$ $\mathrm{KD}$, and taken together, these observations reinforce the idea that Cldn-8d is a barrier-forming TJ protein in fishes or at least in the gill epithelium of trout.

Because efflux rates of $\mathrm{Na}^{+}$and $\mathrm{Cl}^{-}$across cldn-8d $\mathrm{KD}$ preparations increase equally (resulting in unchanged $\left.\mathrm{P}_{\mathrm{Na}} / \mathrm{P}_{\mathrm{Cl}}\right)$, it would suggest that Cldn-8d in the cultured trout gill epithelium acts as an indiscriminate barrier to $\mathrm{Na}^{+}$and $\mathrm{Cl}^{-}$movement. This contrasts with the ionand charge-selectivity that is often reported for CLDN TJ proteins, including CLDN-8 (Günzel \& Yu 2013). However, it is likely to be more complicated than this as mammalian CLDN-8 is reported to act as both a $\mathrm{Na}^{+}$ barrier and $\mathrm{Cl}^{-}$pore depending on cell type (Yu et al. 2003, Hou et al. 2010) as well as contribute to the formation of an impermeable TJ barrier in the urinary bladder (Acharya et al. 2004). The role of Cldn-8d in the electrically tight cultured gill epithelium would certainly be consistent with the latter. However, it should also be noted that the model gill epithelium used in this study is composed of PVCs only, and the role of Cldn-8d in gill ionocytes might not be indiscriminate. It has been reported that cldn-8d transcript abundance is greater in teleost gill ionocytes vs PVCs (Chasiotis et al. 2012a, Kolosov et al. 2014), which could be suggestive of different function. It has also been observed that environmental change can differently alter $c l d n-8 d$ mRNA abundance in gill PVCs and ionocytes (Chasiotis et al. 2012a). Therefore, further work investigating the idea of a cell-specific role for Cldn-8d in the fish gill is warranted.

\section{The contribution of Cldn-8d to cortisol-mediated tightening of the gill epithelium}

In the rainbow trout gill epithelium, $c l d n-8 d$ has been reported to be particularly responsive to corticosteroid treatment (Kelly \& Chasiotis 2011), and the response to cortisol appears to be mediated through both glucocorticoid and mineralocorticoid receptors (Kelly \& Chasiotis 2011). Transcript encoding Cldn-8d is a comparatively abundant cldn isoform in the gill of a number of teleost species, including rainbow trout (Bagherie-Lachidan et al. 2009, Chasiotis \& Kelly 2012, Kolosov et al. 2014). Therefore, it seems logical to consider that cortisol-induced changes in $c l d n-8 d$ abundance may be indicative of a prominent role http://jme.endocrinology-journals.org DOI: 10.1530/JME-17-0108
○ 2017 Society for Endocrinology Printed in Great Britain
Published by Bioscientifica Ltd 
for Cldn-8d in cortisol-induced gill epithelium tightening. This idea is supported by data in the current study, which show that when cortisol treatment is coupled with a $c l d n-8 d$ KD-induced reduction in Cldn-8d abundance, the gill epithelium does not exhibit the same increase in TER and reduction in PEG-400 permeability that can be observed in cortisol-treated control preparations. However, relative to control $c l d n-8 \mathrm{KD}$ preparations, cortisol-treated cldn-8d KD preparations still exhibit higher TER and lower PEG400 permeability. There are likely to be several reasons for this. The first is that other cortisol-responsive cldn isoforms encoding proteins that are currently thought to possess barrier function, continue to exhibit an unperturbed increase in abundance following cortisol treatment of cldn-8d KD preparations. These include $c l d n-6,-20 a,-23 a$, $-28 b,-30$ and -31 , the latter of which encodes Cldn-31, which has recently been confirmed as barrier forming in the gill TJ complex (Kolosov et al. 2017). In addition to Cldns, other TJ proteins that have been reported as cortisol-responsive and barrier forming, such as occludin (Chasiotis et al. 2010) and tricellulin (Kolosov \& Kelly 2013) may also have contributed to a persistent, but suppressed cortisol-induced decrease in permeability of cldn-8d KD preparations. A second reason for observed changes in permeability is that despite effective transcriptional $\mathrm{KD}$, some Cldn-8d is still present in the gill epithelium model. This continues to be responsive to cortisol treatment and most likely contributes to a reduction in permeability. Finally, there is some evidence to suggest that select Cldns may compensate for $c l d n-8 d$ $\mathrm{KD}$, because the abundance of $c l d n-7,-12$ and $-20 a$ mRNAs in cortisol-treated $c l d n-8 d \mathrm{KD}$ epithelia are greater than cortisol-treated control preparations. Transcript encoding Cldn-7 was also reported to mount a compensatory response to cldn-31 KD in the gill epithelium (Kolosov et al. 2017), but alterations in cldn-7 abundance have been associated with epithelial restructuring and the development of confluence rather than the development of resistive properties (Chasiotis et al. 2012a, Kolosov et al. 2014). The roles of $c l d n-12$ and $-20 a$ in gill barrier function are also unclear. For example, previous studies have reported both increased and decreased gill cldn-12 mRNA abundance in association with environmental change that requires enhanced barrier function (Chasiotis \& Kelly 2011b, Chasiotis et al. 2012a, Kolosov et al. 2014). Furthermore, $c l d n-20 a$ has only recently been described in trout as cortisol-responsive in the skin (Gauberg et al. 2017), and in this regard, remains to be investigated in the gill. Studies on other vertebrates provide little insight as to the potential compensatory roles of $c l d n-7,-12$ and $-20 a$ in the manipulated gill epithelium. For instance, CLDN-7 has been reported to act as both an anion barrier and pore (Günzel \& Yu 2013), while in vitro studies suggest that CLDN-12 may modulate paracellular $\mathrm{Ca}^{++}$movement (Fujita et al. 2008). In contrast, CLDN-20 in human breast cancer cells is involved in aggressive phenotype development and in chick embryos, development of the retinal pigment epithelium (Rizzolo et al. 2007, Martin et al. 2014). Therefore, the only clear picture is that if any compensation did occur, it was not enough to counteract increased ion flux in cortisol-treated $c l d n-8 d$ KD epithelia when the model epithelium was exposed to apical FW. Nevertheless, it seems clear that Cldn-8d plays an important role in cortisol-induced tightening of the cultured gill epithelium and under natural conditions this could be important in order to moderate passive ion loss under conditions where a stressor-induced elevation in circulating cortisol occurs.

\section{Conclusion and perspectives}

The idea that cortisol can regulate paracellular solute movement across the FW fish gill epithelium by modulating the physiological properties of the gill TJ complex is well established. However, mechanistic understanding of this phenomenon is almost non-existent. Using a functional approach, this study highlights a barrier-forming role for Cldn-8d between rainbow trout gill epithelium PVCs that is enhanced by cortisol. Moreover, data suggest that other Cldn-8 isoforms in the PVCs of the rainbow trout gill may not be involved in corticosteroid-induced gill epithelium tightening. Given the importance of the gill epithelium as a barrier to solute movement in ectothermic aquatic vertebrates, and the central role of cortisol in teleost fish physiology, these observations bring into focus an emerging sophistication that will require thorough examination. This is important when we take into consideration the critical link between endocrinemediated alterations in the ionoregulatory physiology of aquatic vertebrates and the ability of these organisms to maintain homeostasis in a challenging environment.

Declaration of interest

The authors declare that there is no conflict of interest that could be perceived as prejudicing the impartiality of the research reported.
() 2017 Society for Endocrinology Printed in Great Britain
Published by Bioscientifica Ltd 


\section{Funding}

S P K is funded by Natural Sciences and Engineering Research Council (NSERC) of Canada Discovery Grant. D K received an Ontario Graduate Scholarship and a York University Provost Dissertation Scholarship.

\section{Author contribution statement}

$\mathrm{D} K$ and S P K conceived the study. D K conducted experiments and collected data. D K analyzed the data. S P K and D K drafted and edited the manuscript.

\section{References}

Acharya P, Beckel J, Ruiz WG, Wang E, Rojas R, Birder L \& Apodaca G 2004 Distribution of the tight junction proteins ZO-1, occludin, and claudin-4, -8, and -12 in bladder epithelium. American Journal of Physiology 287 F305-F318. (doi:10.1152/ajprenal.00341.2003)

Amasheh S, Milatz S, Krug SM, Bergs M, Amasheh M, Schulzke J-D \& Fromm M $2009 \mathrm{Na}^{+}$absorption defends from paracellular backleakage by claudin-8 upregulation. Biochemical and Biophysical Research Communications 378 45-50. (doi:10.1016/j. bbrc.2008.10.164)

Angelow S, Schneeberger EE \& Yu ASL 2007 Claudin-8 expression in renal epithelial cells augments the paracellular barrier by replacing endogenous Claudin-2. Journal of Membrane Biology 215 147-159. (doi:10.1007/s00232-007-9014-3)

Antonetti DA, Wolpert EB, DeMaio L, Harhaj NS \& Scaduto RC Jr 2002 Hydrocortisone decreases retinal endothelial cell water and solute flux coincident with increased content and decreased phosphorylation of occludin. Journal of Neurochemistry 80 667-677. (doi:10.1046/j.0022-3042.2001.00740.x)

Bagherie-Lachidan M, Wright SI \& Kelly SP 2009 Claudin-8 and -27 tight junction proteins in puffer fish Tetraodon nigroviridis acclimated to freshwater and seawater. Journal of Comparative Physiology B 179 419-431. (doi:10.1007/s00360-008-0326-0)

Barton BA \& Iwama GK 1991 Physiological changes in fish from stress in aquaculture with emphasis on the response and effects of corticosteroids. Annual Review of Fish Diseases 1 3-26. (doi:10.1016/0959-8030(91)90019-G)

Bui P \& Kelly SP 2014 Claudin-6, -10d and -10e contribute to seawater acclimation in the euryhaline puffer fish Tetraodon nigroviridis. Journal of Experimental Biology 217 1758-1767. (doi:10.1242/ jeb.099200)

Chasiotis H \& Kelly SP 2011a Permeability properties and occludin expression in a primary cultured model gill epithelium from stenohaline freshwater goldfish. Journal of Comparative Physiology $B$ 181 487-500. (doi:10.1007/s00360-010-0535-1)

Chasiotis H \& Kelly SP $2011 b$ Effect of cortisol on permeability and tight junction protein transcript abundance in primary cultured gill epithelia from stenohaline goldfish and euryhaline trout. General and Comparative Endocrinology 172 494-504. (doi:10.1016/j. ygcen.2011.04.023)

Chasiotis H \& Kelly SP 2012 Effects of elevated circulating cortisol levels on hydromineral status and gill tight junction protein abundance in the stenohaline goldfish. General and Comparative Endocrinology 175 277-283. (doi:10.1016/j.ygcen.2011.11.024)

Chasiotis H, Wood CM \& Kelly SP 2010 Cortisol reduces paracellular permeability and increases occludin abundance in cultured trout gill epithelia. Molecular and Cellular Endocrinology 323 232-238. (doi:10.1016/j.mce.2010.02.030)

Chasiotis H, Kolosov D \& Kelly SP 2012a Permeability properties of the teleost gill epithelium under ion-poor conditions. American Journal of Physiology 302 R727-R739. (doi:10.1152/ajpregu.00577.2011)
Chasiotis H, Kolosov D, Bui P \& Kelly SP 2012b Tight junctions, tight junction proteins and paracellular permeability across the gill epithelium of fishes: a review. Respiratory Physiology and Neurobiology 184 269-281. (doi:10.1016/j.resp.2012.05.020)

Donini A \& O'Donnell MJ 2005 Analysis of $\mathrm{Na}^{+}, \mathrm{Cl}-, \mathrm{K}^{+}, \mathrm{H}^{+}$and $\mathrm{NH}_{4}{ }^{+}$ concentration gradients adjacent to the surface of anal papillae of the mosquito Aedes aegypti: application of self-referencing ionselective microelectrodes. Journal of Experimental Biology $\mathbf{2 0 8}$ 603-610. (doi:10.1242/jeb.01422)

Evans DH, Piermarini PM \& Choe KP 2005 The multifunctional fish gill: dominant site of gas exchange, osmoregulation, acid-base regulation, and excretion of nitrogenous waste. Physiological Reviews 85 97-177. (doi:10.1152/physrev.00050.2003)

Farquhar MG \& Palade GE 1963 Junctional complexes in various epithelia. Journal of Cell Biology 17 375-412. (doi:10.1083/ jcb.17.2.375)

Förster C, Silwedel C, Golenhofen N, Burek M, Kietz S, Mankertz J \& Drenckhahn D 2005 Occludin as direct target for glucocorticoidinduced improvement of blood-brain barrier properties in a murine in vitro system. Journal of Physiology 565 475-486. (doi:10.1113/ jphysiol.2005.084038)

Fujita H, Sugimoto K, Inatomi S, Maeda T, Osanai M, Uchiyama Y, Yamamoto Y, Wada T, Kojima T, Yokozaki H, et al. 2008 Tight junction proteins claudin-2 and -12 are critical for vitamin D-dependent $\mathrm{Ca}^{2+}$ absorption between enterocytes. Molecular Biology of the Cell 19 1912-1921. (doi:10.1091/mbc.E07-09-0973)

Furuse M, Fujita K, Hiiragi T, Fujimoto K \& Tsukita S 1998 Claudin-1 and -2 : novel integral membrane proteins localizing at tight junctions with no sequence similarity to occludin. Journal of Cell Biology 141 1539-1550. (doi:10.1083/jcb.141.7.1539)

Gauberg J, Kolosov D \& Kelly SP 2017 Spatial response of claudin tight junction proteins in teleost fish skin to elevated cortisol levels. General and Comparative Endocrinology 240 214-226. (doi:10.1016/j. ygcen.2016.10.006)

Günzel D \& Yu ASL 2013 Claudins and the modulation of tight junction permeability. Physiological Reviews 93 525-569. (doi:10.1152/ physrev.00019.2012)

Hou J, Renigunta A, Yang J \& Waldegger S 2010 Claudin-4 forms paracellular chloride channel in the kidney and requires claudin-8 for tight junction localization. PNAS 107 18010-18015. (doi:10.1073/pnas.1009399107)

Katoh M \& Katoh M 2003 CLDN23 gene, frequently downregulated in intestinal - type gastric cancer, is a novel member of the CLAUDIN gene family. International Journal of Molecular Medicine 11 683-689. (doi:10.3892/ijmm.11.6.683)

Kelly SP \& Wood CM 2001 Effect of cortisol on the physiology of cultured pavement cell epithelia from freshwater trout gills. American Journal of Physiology 281 R811-R820.

Kelly SP \& Wood CM 2002 Cultured gill epithelia from freshwater tilapia (Oreochromis niloticus): effect of cortisol and homologous serum supplements from stressed and unstressed fish. Journal of Membrane Biology 190 29-42. (doi:10.1007/s00232-002-1020-x)

Kelly SP \& Wood CM 2008 Cortisol stimulates calcium transport across cultured gill epithelia from freshwater rainbow trout. In Vitro Cellular and Developmental Biology - Animal 44 96-104. (doi:10.1007/s11626007-9077-6)

Kelly SP \& Chasiotis H 2011 Glucocorticoid and mineralocorticoid receptors regulate paracellular permeability in a primary cultured gill epithelium. Journal of Experimental Biology 214 2308-2318. (doi:10.1242/jeb.055962)

Kelly SP, Fletcher M, Part P \& Wood CM 2000 Procedures for the preparation and culture of 'reconstructed' rainbow trout branchial epithelia. Methods in Cell Science 22 153-163. (doi:10.1023/ A:1009816923262)

Kiuchi-Saishin Y, Gotoh S, Furuse M, Takasuga A, Tano Y \& Tsukita S 2002 Differential expression patterns of claudins, tight junction 
membrane proteins, in mouse nephron segments. Journal of the American Society of Nephrology 13 875-886. (doi:10.1152/ ajpregu.00086.2013)

Kolosov D \& Kelly SP 2013 A role for tricellulin in the regulation of gill epithelium permeability. American Journal of Physiology-Regulatory, Integrative and Comparative Physiology 304 R1139-R1148.

Kolosov D \& Kelly SP 2016 Dietary salt loading and ion-poor water exposure provide insight into the molecular physiology of the teleost fish gill epithelium tight junction complex. Journal of Comparative Physiology B 186 739-757. (doi:10.1007/s00360-016-0987-z)

Kolosov D, Bui P, Chasiotis H \& Kelly SP 2013 Claudins in teleost fishes. Tissue Barriers 1 e25391. (doi:10.4161/tisb.25391)

Kolosov D, Chasiotis H \& Kelly SP 2014 Tight junction protein gene expression patterns and changes in transcript abundance during development of model fish gill epithelia. Journal of Experimental Biology 217 1667-1681. (doi:10.1242/jeb.098731)

Kolosov D, Donini A \& Kelly SP 2017 Claudin-31 contributes to corticosteroid-induced alterations in the barrier properties of the gill epithelium. Molecular and Cellular Endocrinology 439 457-466. (doi:10.1016/j.mce.2016.10.034)

Kwong RWM \& Perry SF 2013 Cortisol regulates epithelial permeability and sodium losses in zebrafish exposed to acidic water. Journal of Endocrinology 217 253-264. (doi:10.1530/JOE-12-0574)

Li WY, Huey CL \& Yu ASL 2004 Expression of claudin-7 and -8 along the mouse nephron. American Journal of Physiology - Renal Physiology 286 F1063-F1071. (doi:10.1152/ajprenal.00384.2003).

Loh YH, Christoffels A, Brenner S, Hunziker W \& Venkatesh B 2004 Extensive expansion of the claudin gene family in the teleost fish, Fugu Rubripes. Genome Research 14 1248-1257. (doi:10.1101/ gr.2400004)

Martin TA, Lane J, Ozupek H \& Jiang WG 2014 Claudin-20 promotes an aggressive phenotype in human breast cancer cells. Tissue Barriers 1 e26518. (doi:10.4161/tisb.26518)

Morita K, Furuse M, Fujimoto K \& Tsukita S 1999 Claudin multigene family encoding four-transmembrane domain protein components of tight junction strands. PNAS 96 511-516. (doi:10.1073/ pnas.96.2.511)
Perry SF \& Laurent P 1989 Adaptational responses of rainbow trout to lowered external $\mathrm{NaCl}$ concentration: contribution of the branchial chloride cell. Journal of Experimental Biology 147 147-168.

Rizzolo LJ, Chen X, Weitzman M, Sun R \& Zhang H 2007 Analysis of the RPE transcriptome reveals dynamic changes during the development of the outer blood-retinal barrier. Molecular Vision 13 1259-1273.

Simon DB, Lu Y, Choate KA, Velazquez H, Al-Sabban E, Praga M, Casari G, Bettinelli A, Colussi G, Rodriguez-Soriano J, et al. 1999 Paracellin-1, a renal tight junction protein required for paracellular $\mathrm{Mg}^{2+}$ resorption. Science 285 103-106. (doi:10.1126/ science.285.5424.103)

Stelwagen K, McFadden HA \& Demmer J 1999 Prolactin alone or in combination with glucocorticoids enhances tight junction formation and expression of the tight junction protein occludin in mammary cells. Molecular and Cellular Endocrinology 156 55-61. (doi:10.1016/ S0303-7207(99)00145-8)

Van Itallie CM \& Anderson JM 2006 Claudins and epithelial paracellular transport. Annual Review of Physiology 68 403-429. (doi:10.1146/ annurev.physiol.68.040104.131404)

Wood CM \& Pärt P 1997 Cultured branchial epithelia from freshwater fish gills. Journal of Experimental Biology 200 1047-1059.

Wood CM, Gilmour KM \& Pärt P 1998 Passive and active transport properties of a gill model, the cultured branchial epithelium of the freshwater rainbow trout (Oncorhynchus mykiss). Comparative Biochemistry and Physiology A 119 87-96. (doi:10.1016/S10956433(97)00403-0)

Yu ASL, Enck AH, Lencer WI \& Schneeberger EE 2003 Claudin-8 expression in Madin-Darby canine kidney cells augments the paracellular barrier to cation permeation. Journal of Biological Chemistry 278 17350-17359. (doi:10.1074/jbc.M213286200)

Zall DM, Fisher D \& Garner MQ 1956 Photometric determination of chlorides in water. Analytical Chemistry 28 1665-1668. (doi:10.1021/ ac60119a009)

Zettl KS, Sjaastad MD, Riskin PM, Parry G, Machen TE \& Firestone GL 1992 Glucocorticoid formation of tight junctions in mouse mammary epithelial cells in vitro. PNAS 89 9069-9073. (doi:10.1073/pnas.89.19.9069)

Received in final form 11 July 2017

Accepted 24 July 2017

Accepted Preprint published online 24 July 2017 http://jme.endocrinology-journals.org

DOI: 10.1530/JME-17-0108
() 2017 Society for Endocrinology Printed in Great Britain 